\title{
Contribuições da Terapia Ocupacional Social nas escolas do campo
}

\author{
Magno Nunes Farias ${ }^{1}$, Wender Faleiro ${ }^{2}$ \\ ${ }^{1}$ Universidade Federal de Goiás - UFG. Unidade Especial de Educação. Av. Dr. Lamartine Pinto de Avelar, \\ 1120. Setor Universitário. Catalão - GO. Brasil. magnonfarias@ hotmail.com. ${ }^{2}$ Universidade Federal de Goiás - \\ UFG.
}

RESUMO. Atualmente busca-se constituir escolas do campo que tenham como diretrizes os princípios da Educação do Campo, ou seja, articuladas com as lutas e modos de vida do campo, sendo uma construção que necessita de interdisciplinaridade. Assim, é um espaço possível de contribuições da Terapia Ocupacional Social (TO Social), tendo em vista que suas ações têm como objetivo a desconstrução das contradições (reprodução de padrões de desigualdade socioeconômica, epistêmica, cultural e territorial) dos sistemas de ensino. Com o objetivo de compreender as possibilidades de atuação da profissão nas escolas do campo, realizou-se um estudo reflexivo e crítico. A TO Social vai atuar nas escolas do campo fortalecendo os processos da Educação do Campo, assegurando o acesso da população do campo aos seus direitos sociais, em especial educacionais, articulando ações terapêuticas ocupacionais para ajudar a promover nos ambientes escolares do campo uma escola que esteja focada nas necessidades sociais dos camponeses, e que não reproduza qualquer tipo de opressão institucional. Algumas ações podem ser: construção de atividades, dinâmicas e projetos, constituindo espaços coletivos ou grupais; acompanhamentos singulares e territoriais; articulação de recursos no campo social; e na dinamização da rede de serviços. Portanto, essa atuação tem possibilidades que podem contribuir para a construção de uma escola verdadeiramente articulado com a vida dos sujeitos do campo.

Palavras-chave: Educação do Campo, Escolas do Campo, Terapia Ocupacional Social. 


\title{
The contributions of Social Occupational Therapy at the rural schools
}

\begin{abstract}
The aim is to constitute Rural Schools that have as guidelines the principles of Rural Education, in others words, guidelines which are articulated with the struggles and lifestyles of the field, being a construction that requires interdisciplinarity. Therefore, it's a possible space for contributions of Social Occupational Therapy (OT), considering that its actions aimed on the deconstruction of the educational system contradictions. In order to investigate the possibilities of professional performance at the Rural Schools, it was carried out a reflexive critical study. The OT will strengthen the process of Rural Education, ensuring the access of people from the field to their social rights, specialty educational rights, articulating occupational therapy actions to help promoting in rural school environments an institution that is focused on the social needs of the farmers who don't represent any kind of institutional oppression. Some actions may be: the construction of activities, dynamics and projects, constituting collective or group spaces; natural and territorial accompaniments; articulation of social resources; and the boosting of network services. Therefore, this actuation has possibilities that may contribute to the institutionalization of this service, truly articulated with peasant demands and their culture.
\end{abstract}

Keywords: Rural Education, Rural Schools, Social Occupational Therapy. 


\section{Contribuciones de La Terapia Ocupacional Social en las escuelas del campo}

RESUMEN. Actualmente busca establecerse escuelas del campo teniendo como directrices los principios de la Educación del Campo, o sea, estrechamente vinculado las luchas y la forma de vida del campo, siendo una construcción que requiere interdisciplinario. Siendo un espacio para el trabajo de la Terapia Ocupacional Social (TO), teniendo en cuenta que sus acciones objetivan la deconstrucción de las contradicciones educativas. Con el fin de investigar las oportunidades de acción de la profesión en las escuelas del campo, llevamos a cabo un estudio crítico reflexivo. La TO actuará para fortalecer los procesos de Educación del Campo, garantizando el acceso de la población rural a los derechos sociales, en particular la educación, con acciones terapéuticas ocupacionales para ayudar a promover una escuela que está estrechamente ligada con necesidades sociales de los campesinos, que no juegan ningún tipo de opresión. Algunas acciones pueden ser: la construcción de actividades, dinámicas y proyectos, constituyendo espacios colectivos o grupales; acompañamientos singulares y territoriales; articulación de recursos en el ámbito social; y la estimulación de las redes de servicios. Esta actuación tiene posibilidades que pueden contribuir con la institucionalización de este servicio, realmente se articulan con las demandas sociales del campesinado.

Palabras clave: Educación del Campo, Escuela del Campo, Terapia Ocupacional Social. 


\section{Introdução}

A Educação do Campo é um movimento sócio-político, cultural e educacional que tem seu nascimento nos movimentos sociais dos trabalhadores e trabalhadoras do campo, sendo esses seus principais protagonistas, e tem por finalidade lutar pela democratização da terra e do acesso ao conhecimento para as populações do campo. Busca uma educação que compreenda as questões históricas, sociais, políticas, culturais e territórios dos povos do campo, que leve em conta suas existências como sujeitos de direito. Desta forma, a luta da Educação do Campo é por justiça social, atrelada com a democratização da terra, articulando por um desenvolvimento do campo voltado para os modos de vida camponeses, se contrapondo a hegemonia do capital (pautados no Agronegócio e Neoliberalismo) (Caldart, 2012, 2008). Além disso, o movimento tem a escola do campo como uma das suas perspectivas, que busca referências nas iniciativas educacionais dos movimentos sociais do campo, e se contrapõe a um modelo de escola que dialoga com a lógica do capital, pauta-se então em uma forma escolar enraizada na cultural, luta e resistência da classe trabalhadora do campo (Molina \& Sá, 2012).
Assim, o objetivo deste artigo foi discorrer sobre possíveis atuações da Terapia Ocupacional Social nos contextos das escolas do campo, tendo em vista que a construção desse modelo de escola (devido à história e a conjuntura do Brasil, pautadas em uma concepção escolar capitalista/urbanocêntrica) tem grandes desafios pela frente, sendo fundamental uma atuação interdisciplinar para o enfrentamento dos modelos hegemônicos e a difusão dessa perspectiva contra hegemônica.

Essa reflexão sobre a atuação surge haja vista as potencialidades da Terapia Ocupacional Social para atuar junto a populações historicamente marginalizadas e que necessitam de justiça social. A profissão utiliza tecnologias sociais individuais e grupais nas escolas, capazes de contribuir para superar as contradições sociais, dando luz e protagonismo para a existência dos sujeitos do campo.

\section{Terapia Ocupacional Social e Educação}

A Terapia Ocupacional é uma profissão que exige ensino superior, que vem se difundindo no Brasil desde 1950, oferecida em diversas universidades brasileiras. Historicamente a atuação da Terapia Ocupacional vem se consolidando na área da educação com ações vinculadas 
principalmente à educação especial, com o objetivo de integrar sujeitos com deficiência física, sensorial e transtornos mentais ou globais do desenvolvimento no contexto escolar, a partir de um conjunto de atividades dirigidas ao indivíduo e ao coletivo com estratégias como recreação, tecnologias assistivas, recursos tecnológicos e ações com os educadores, familiares e estudantes (Lopes \& Silva, 2007; Rocha, 2007). Assim, “a inserção dos terapeutas ocupacionais no processo de inclusão escolar parece ser uma consequência da comunicação da profissão com a educação especial e com os processos de inclusão social em geral" (Cardoso \& Matsukura, 2012, p. 08).

A Terapia Ocupacional na educação especial se dá desde 1960 (Bartalotti, 2007). Porém, atualmente as possibilidades de atuação da Terapia Ocupacional nos contextos educacionais vêm se ampliando, superando a área restrita de educação especial. Isso pode ser visto pelas ações que vem sendo produzidas pelo projeto Metuia, que foi criado em 1998 (Lopes \& Silva, 2007) e desenvolve ações Terapêuticas Ocupacionais no campo social, desenvolvendo então as concepções da Terapia Ocupacional Social (TO Social) no Brasil. Nesse sentido, a TO Social vem atuando em contextos educacionais, tendo como base recortes teórico-metodológicos capazes de promover uma leitura sócio-histórica e cultural da realidade, a partir de uma perspectiva macrossocial para compreender as questões microssociais, sendo norteado por referenciais pautados em disciplinas como sociologia, antropologia, educação e filosofia, superando a racionalidade da educação especial (voltada para aspectos da saúde) (Lopes, Borba \& Cappellaro, 2011).

Desta forma, a TO Social no campo educacional se coloca sob as contradições do sistema educacional, relacionadas à reprodução de padrões de desigualdade territorial, racial, de gênero, social, econômico e cultural. Tendo em vista que "na sociedade brasileira, assim como na realidade de muitos países, a constituição sócio-histórica desenha padrões de desigualdades sociais relevantes, que marcam grande parte de sua população" (Lopes et al., 2010, p. 141), sendo a escola uma das vias que perpetuam essas desigualdades.

De acordo com Malfitano (2005), a atuação da TO Social no campo da educação se debruça sobre os processos de exclusão desenvolvidos no sistema educacional, nessa concepção busca-se colocar em voga os movimentos educacionais que historicamente tendem a excluir minorias sociais. Tendo em vista 
que a escola se caracteriza como aparelho ideológico do Estado que teve em sua consolidação a função social de institucionalizar a reprodução do sistema capitalista, que por sua vez tende a utilizálo como sistema para assegurar relações de dominação sobre classes oprimidas e exploradas (Althusser, 1970). Notam-se essas questões principalmente nos acessos diferenciados à educação para as diferentes classes, enquanto as classes populares possuem acesso à educação historicamente negados ou de baixa qualidade, as classes dominantes possuem seus acessos facilitados e livres de quaisquer movimentos tendenciosos, tendo seus desenvolvimentos educacionais livres de qualquer amarra institucional que os oprima (Saviani, 2008).

Assim, a TO Social vem contribuindo para superação da (re)produção dessas desigualdades no sistema educacional, com a finalidade de desenvolver ações terapêuticas ocupacionais que promovam a justiça social, para que a escola seja um espaço intercultural, acolhedor e que respeite toda a diversidade existencial, social, econômica e cultural dos sujeitos. Um dos exemplos dessa atuação é descrita por Silva (2016), que narra a atuação da TO na reinserção escolar de um jovem com dificuldades de vivenciar o contexto escolar, produzindo estratégias para a superação de um sistema educacional excludente, que exige padrões de comportamentos que não dialogam com as realidades de jovens em contextos de vulnerabilidades sociais. Compreendendo que nesse sentido a TO Social almeja ultrapassar o paradigma de atuação fundada no processo saúde-doença, mas busca debruçar-se sobre as questões sociais, educacionais, e demais aspectos relacionados à desigualdade socioeconômica e cultural, pautando-se na participação e justiça social.

Desta forma, a TO Social busca contribuir para um contexto educacional inclusivo, que não reproduza padrões de opressão. Além disso, sua atuação pauta-se na defesa de uma educação pública de qualidade, e que forme sujeitos críticos, almejando a escola enquanto espaço de libertação e conscientização (Freire, 1967), com base em suas tecnologias sociais (ações individuais e coletivas para construção de um espaço escolar acolhedor e que valorize as potencialidades dos sujeitos).

\section{Educação do Campo: resistência em meio a contradições}

Como foi dito anteriormente, a escola historicamente se constrói a partir das contradições, e se torna aparelho 
reprodutor das desigualdades. Assim, a escola reproduz a divisão "social-técnica do trabalho, pelas regras da ordem estabelecida pela dominação de classe” (Althusser, 1970, p. 21), os sistemas se organizam para assegurar o acesso ao conhecimento diferencial para o operário e burguês. $\mathrm{O}$ primeiro possui um acesso que o leva a profissões de exploração pela lógica capitalista (proletariado assalariado), e os outros possuem acesso para tornarem-se agentes da exploração ou capitalistas (dirigentes, empresários). Além disso, a escola acaba por se configurar como sistema de "inculcação" que tende a impregnar as massas populares que seus lugares nas relações sociais só devem se estabelecer na posição de explorados, e acabam os oferecendo formações alienantes, com conhecimentos que são direcionados para a capacitação de mão de obra assalariada. Dessa maneira, a escola “em lugar de instrumento de equalização social constitui um mecanismo construído pela burguesia para garantir e perpetuar seus interesses". (Saviani, 2008, p. 25-26).

A partir dessas ambiguidades, abrese caminho para se discutir a permanência dessas contradições no cenário atual nacional. Apesar do processo de democratização do acesso à educação, a partir da Constituição Federal de 1988, que a coloca como direito de todos e dever do
Estado, e a Lei de Diretrizes e Bases da Educação $n^{\circ}$ 9394/96, que ratifica o direito à educação e o acesso de todos a mesma de forma igualitária, notamos que ainda há muitas contradições na organização da educação no Brasil, contradições essas que são legitimadas pelo Estado. Um exemplo disso são as políticas Neoliberais, que têm se instituído sobre as políticas educacionais desde a década de 1990.

De acordo com Bezerra (2011), com a crise da década de 1970 as políticas keynesianas não conseguiram mais sustentar a estrutura de Estado de bemestar social e dar uma resposta efetiva à crise, o que levou a uma recessão global. Assim, buscou-se uma saída para a crise de cunho burguês, com a institucionalização do neoliberalismo, que chegou ao Brasil na década de 1990 e se consolidou como modelo hegemônico. Sua execução ocorreu fortemente no governo de Fernando Henrique Cardoso, com os processos de reestruturação Estatal. O movimento neoliberal aponta que a crise é fruto do Estado intervencionista, sendo necessário para superá-la a construção de um Estado Mínimo, que desse mais abertura para regulações do mercado. Essa racionalidade leva a duas consequências: formação de um programa ofensivo de equilíbrio fiscal, com desestruturações administrativas, previdenciárias e trabalhistas, e 
principalmente com corte das políticas sociais; e a desregulação do mercado financeiro do trabalho, privatizações $\mathrm{e}$ abertura comercial (Saviani, 2008).

Para Guhur e Silva (2009, p. 86), quando os movimentos neoliberais "atacam o Estado como causador de todos os males, o que os neoliberais querem atacar na verdade é o sistema público de seguridade social, que, em menor ou maior grau, foi construído no período histórico anterior", com o objetivo de descontruir essa estrutura conquistada pelos movimentos da classe trabalhadora. Além disso, o argumento para esse movimento foi posto a partir da noção de que a crise ocorreu por causa dos gastos sociais. Porém, Montaño (2007) coloca que essa ideia foi apenas uma justificativa para remover os direitos sociais da população, já que a ausência de recursos do Estado tem como causas: as privatizações de empresas, o clientelismo, a corrupção política e a sonegação, as falências de empresas, a informatização do trabalho e o largo desemprego.

Esse cenário leva a grandes ambiguidades, ao mesmo tempo em que há uma expansão das políticas educacionais para a universalização do acesso à educação básica, há um projeto societário neoliberal, que inviabiliza a materialização dessas políticas, com fortes cortes em gastos sociais, tendo em vista $\mathrm{O}$ afastamento do Estado da educação, abrindo lugar para o mercado autorregulador. Assim, o papel do Estado se reduz passando a garantir o

... mínimo de educação possível para os "perdedores", aqueles que, seja por sua "natureza humana inferior", seja por um infortúnio, sucumbiram no mercado. Alternativamente, a educação em livre metabolismo com o mercado seria a mais adequada, pois ensinaria às crianças e aos jovens a virtude do individualismo e da ordem social competitiva (Leher \& Motta, 2012, p. 577).

Essa perspectiva meritocrata e excludente, que tende a legitimar e perpetuar as desigualdades sociais (dentro da perspectiva neoliberal), e acaba produzindo uma pedagogia da exclusão (Gentili, 1995), perpetua o fracasso das classes mais pobres, pois, nessa conjuntura quem tem acesso à educação de qualidade é quem possui recursos financeiros. A educação também se consolida como mercadoria, com a expansão das escolas particulares, e deseja romper com a educação pública, universal e de qualidade, a partir de intervenções como a privatizante e a descentralização autoritária. Além disso, utiliza-se como estratégia a inauguração de um movimento de reforma ideológica, objetivando acabar com a possibilidade de uma educação democrática e pública, instituindo modos 
de exclusão de grupos socialmente e historicamente marginalizados a um sistema escolar de qualidade (Costas Jr., 2010).

Assim, há dois movimentos neoliberalistas: a mercantilização da educação e o ataque à escola pública, que acabam inviabilizando o acesso de qualidade unicamente das populações marginalizadas e pobres. Institucionalizando assim a inclusão excludente (Kuenzer, 2005 apud Saviani, 2008) da população pobre, que inclui os estudantes em sistemas escolares diversos (diferentes níveis e modalidades) sem padrões exigidos para a entrada efetiva no mercado de trabalho, ou seja, com baixos padrões de qualidade. Gerando um futuro de exclusão do mercado de trabalho e da participação desses sujeitos em sociedade, sendo mão de obra para trabalhos desvalorizados socialmente, ou seja, se tornam mão de obra exploradas pela lógica alienante capitalista (Saviani, 2008).

Uma das populações fortemente atingidas por esses processos, tanto da exclusão história pelo sistema educacional reprodutivista quanto pela ofensiva neoliberal excludente, são as populações do campo. Com isso, se dá na década de 1980 uma forte mobilização dos Movimentos Sociais do campo (protagonizado pelo Movimento dos
Trabalhadores Sem Terra - MST), em favor de processos educacionais que efetivamente coloquem esses sujeitos como protagonista, surgindo assim o Movimento Educação do Campo. Que se caracteriza como um Movimento sóciopolítico brasileiro, que tem como agentes as trabalhadoras e trabalhadores do campo, que busca a partir de ações de luta e resistência agir sobre as políticas educacionais e os diversos acessos a direitos sociais que foram negados historicamente a essas comunidades, e ainda são negados (Caldart, 2012).

A Educação do Campo se fortalece como movimento a partir dos anos 1980, com o período de redemocratização, onde há uma abertura para o surgimento e fortalecimento dos Movimentos Sociais do campo, que foram reprimidos e quase extintos no período militar. É nessa década que surge o MST, um dos sujeitos mais importantes para tornar o campo um lugar com visibilidade dentro das políticas públicas. Além disso, o movimento também se fortalece com a Constituição Federal de 1988, e a Lei de Diretrizes e Bases da Educação de 1996, que legitimam suas pautas de luta, potencializam suas ações por um desenvolvimento camponês pautado nos direitos humanos e na justiça social (Oliveira \& Campos, 2012). 
A Educação do Campo é um movimento que tem por finalidade superar a Educação Rural, por isso é essencial a afirmação da nomenclatura nos diversos espaços de debates e nas políticas públicas. Ela tem uma relação antagonista com a Educação Rural, que foi um movimento que permeou o campo principalmente a partir da metade do século $\mathrm{XX}$, com objetivo de utilizar o sistema escolar para alienar o homem e a mulher do campo, e adaptá-los para um modo de vida produtivista, dentro da lógica de produção urbana e agro capitalista, para que esses se tornassem mão de obra assalariada em prol do capital. Além disso, tinha a concepção do campo como lugar de atraso, idealizando o urbano como espaço de desenvolvimento, reproduzindo práticas discriminatórias (Oliveira \& Campos, 2012). Desta maneira, a nomenclatura Educação do Campo afirma o projeto político, social e cultura contra hegemônica, com o objetivo emancipador das populações do campo, compreendendo suas lutas, culturas e modos de vida, ou seja, suas existências.

Assim, busca-se superar políticas públicas que "quando pensaram a especificidade da população trabalhadora do campo sempre o fizeram na perspectiva do "para"; nem "com" e muito menos "dos" trabalhadores" (Caldart, 2008, p.
72). Sendo fundamental a institucionalização e discussão que carreguem sempre a nomenclatura Educação DO Campo, pois apesar de transitar em vários espaços, nunca se deve esquecer que ela surge e é do campo, tendo como protagonistas os sujeitos que o constituem.

A Educação do Campo reside sobre duas concepções, que só é possível a emancipação dos sujeitos do campo com democratização do acesso ao conhecimento e a terra (Molina, 2010), ela dialoga com um novo modelo de desenvolvimento do campo. Dessa forma, esse movimento está relacionado também com a Reforma Agrária, superando os processos capitalistas - principalmente do Agronegócio - que invadem o campo brasileiro desde o século XX, levando a expropriação da terra e a exploração dos sujeitos que nele residem, os negando direitos fundamentais de existência. Assim, a Educação do Campo se insere nesse percurso de

Democratização da terra, com a democratização do acesso ao conhecimento, para que os sujeitos coletivos possam, a partir do acesso à terra e aos recursos naturais, ter estabelecido novos patamares para criação de condições que lhes garantam, a si e a sua família, novas condições de vida com dignidade. (Molina, 2009, p. 189). 
A Educação do Campo supera questões restritas à educação e pedagogia, perpassa pelo trabalho no campo, suas dimensões culturais e suas relações de produção e sociais camponesas. Essa dimensão trabalho-educação marca fortemente essa movimentação. Porém, essa relação se dá a partir da concepção do trabalho que supera a concepção capitalista de trabalho alienado, e esta educação tem como finalidades a articulação com o trabalho a partir da ideia desse como processo fundamental para a transformação e humanização dos sujeitos, de forma emancipatória e socialista. Tendo em vista que a Educação do Campo tem como objetivo a formação humana, lidando com os sujeitos concretos, em suas múltiplas dimensões, "orienta a pensar a educação colada à vida real, suas contradições, sua historicidade; a pretender educar os sujeitos para um trabalho não alienado; para intervir nas circunstâncias objetivas que produzem o humano". (Caldart, 2008, p. 78).

Dentro dessa perspectiva, a Educação do Campo tem a escola como espaço de direito dos sujeitos do campo, a colocando como "uma aliada dos sujeitos sociais em luta para poderem continuar existindo enquanto camponeses". (Molina, 2015, p. 149), e assim garantir os modos de vida, existência material, social, cultural e territorial desses povos. Porém, admite-se também que não deve centrar os ideais do movimento na escola, o acesso a ela é uma das perspectivas do movimento, enquanto política pública fundamental para a constituição dos sujeitos, não podendo ficar refém da escola como único espaço formativo, tendo em vista que os processos formativos do campo são múltiplos, e se dão principalmente nos processos de luta e resistência.

\begin{abstract}
A materialidade educativa de origem da Educação do Campo está nos processos formadores dos sujeitos coletivos da produção e das lutas sociais do campo. Por isso, ela desafia o pensamento pedagógico a entender estes processos, econômicos, políticos, culturais, como formadores do ser humano e, portanto, constituintes de um projeto de educação emancipatória, onde quer que ela aconteça, inclusive na escola (Caldart, 2008, p. 81).
\end{abstract}

Assim, afirma-se que as escolas do campo são uma perspectiva e um objetivo do Movimento de Educação do Campo, não sendo o único, porém fundamental para a materialidade do movimento. A idealização das escolas do campo foi gerada no Movimento de Educação do Campo, partindo das experiências de formação de sujeitos dos Movimentos Sociais que lutam pela terra e pelo acesso à educação. Assim, essa concepção de escola surge das contradições social, das lutas e práticas dos Movimentos Sociais 
camponeses dos trabalhadores e trabalhadoras do campo, sendo uma resposta aos movimentos educacionais hegemônicos/neoliberais e capitalista, se contrapondo a projetos escolares que objetivam sujeitar o sujeito do campo ao sistema do capital. "O movimento histórico de construção da concepção de escola do campo faz parte do mesmo movimento de construção de um projeto de campo e de sociedade pelas forças sociais da classe trabalhadora, mobilizada no movimento atual na disputa contra-hegemônica". (Molina \& Sá, 2012, p. 324-325).

A escola do campo é um local que contempla e necessita de ações interdisciplinares ${ }^{\mathrm{i}}$, com a atuação de diversos profissionais, como o terapeuta ocupacional social, juntamente com os profissionais da educação que já atuam ali, para contribuir nos processos educacionais e nas dinâmicas das relações. De acordo com Munguba (2008, p. 02), “ao se somarem os conhecimentos específicos, produz-se área de conhecimento e atuação que responda as demandas sociais", assim, os vários núcleos de saberes produzem uma rede de intervenção sólida para dar conta das necessidades sociais educacionais dos educandos do campo em seus contextos escolares.
Trata-se de um estudo de análise reflexiva e crítica, a partir do aprofundamento na literatura sobre as duas temáticas (TO Social e Escolas do Campo), com objetivo descritivo-exploratório. Nessa perspectiva, o aprofundamento na literatura possibilitou ter maior compreensão sobre as temáticas da Escolas do Campo e TO Social separadamente, para que subsidiassem a reflexão crítica sobre as possibilidades e contribuições da TO Social para esse projeto de escola. Assim, o estudo se caracteriza como descritivo-exploratório pelo fato de descrever questões sobre os temas estudados, com objetivo de ampliar as possibilidades de reflexão, e assim explorar mais a questão, deixando suas tramas mais explicitas para a construção de hipóteses e possibilidades inovadoras (Silveira \& Córdova, 2009). Ainda são escassos os estudos que discorrem sobre a ação da TO Social na Escola, e são inexistentes estudos sobre sua atuação específica na escola do campo. Assim, propôs-se aqui realizar uma reflexão crítica sobre as possibilidades dessa atuação para subsidiar futuras reflexões, e, sobretudo, práticas da TO Social nesses espaços.

\section{Resultados e discussão}

\section{Metodologia}


Tendo em vista a Educação do Campo como movimento de luta da classe trabalhadora do campo, a fim de desencadear processos contra hegemônicos para o desenvolvimento do campo, podemos observá-lo como espaço que produz demandas para a TO Social. Podendo essa contribuir nos movimentos instituintes, como nas escolas do campo, sendo esses espaços de formação fundamentais para a constituição de movimento emancipatório para o campo.

Para isso, é fundamental que a TO Social reconheça a escola do campo como espaço de vinculação com os sujeitos concretos do campo, tendo esses como protagonistas da escola como uma perspectiva da Educação do Campo. Além disso, deve-se se ater a possibilidade da escola como lugar de libertação, que permite a visibilidade social de grupos marginalizados, amplia a possibilidades de vivenciar e experenciar o mundo de modo emancipatório, e também como instrumento fundamental para melhorar condições de vida (Lopes \& Silva, 2007). Assim, apesar das contradições é fundamental recorrer a uma concepção da educação como prática da liberdade, sendo a educação das classes oprimidas fundamental, educação "desvestida da roupagem alienada e alienante, seja uma força de mudança e de libertação". (Freire,
1967, p. 36) com base na concepção do homem-sujeito. Sendo essencial que a TO se conscientize como agente social a partir dessas leituras críticas sobre a educação, levando em conta seu potencial transformador, mas sem ser ingênua ao ponto de não criticar as concepções excludentes instituídas.

Partindo dessa premissa, compreende-se que pelos fatores históricos e as conjunturas políticas esse projeto de escola do campo é um desafio para sociedade, tendo em vista que as ideias de escolas públicas estão enraizadas em uma lógica urbano-centrada e mercadológica. Sendo assim, a atuação da TO Social pode ser fundamental na construção desse novo projeto escolar nas comunidades do campo, para assim atingir um novo projeto societário libertador dos sujeitos camponeses.

A TO Social tem como finalidade agir dentro das contradições educacionais, e tendo em vista os processos socais que marginalizaram e ainda marginalizam os povos do campo, tem como papel dentro do contexto escolar do campo lançar ações direcionadas para o reconhecimento político, social e cultural do direito dos povos do campo. Legitimando e fortalecendo a existência digna em todas as suas etapas de vida dos camponeses, consolidando a construção de um sistema 
educativo voltada para a vida no campo, legitimando-os como sujeitos de direitos (Molina, 2006). Para que possibilidade de uma nova ordem desenvolvimento do campo, seja atingida

... o território do campo deve ser compreendido para muito além de um espaço de produção agrícola. $\mathrm{O}$ campo é território de produção de vida; de produção de novas relações sociais; de novas relações entre os homens e a natureza; entre o rural e o urbano. O campo é um território de produção de história e cultura, de luta de resistência dos sujeitos que ali vivem (Molina, 2006, p. 8).

Assim, a TO Social irá transitar sobre as questões que geram conflitualidades nos espaços do campesinato brasileiro, como as questões políticas que desenvolveram e ainda desenvolvem uma educação para o campo alienadora, e sobre as questões de caráter ideológicos, que muitas vezes inculcam nesses sujeitos a necessidade de desraizamento do campo, que deslegitimam seus modos de vida e cultura, a partir da Ideologia Civilizatória, que coloca o campo como lugar de atraso e o urbano de progresso (Cruz, Araújo \& Costa, 2015; Carvalho, 2011). Além disso, é imprescindível que questões relacionadas aos movimentos do Agronegócio sejam levadas em consideração na atuação profissional, já que esses processos são devastadores para o campesinato brasileiro, por imporem a esses sujeitos um padrão de produção desarticulando com seus recursos culturais, familiares, comunitários, que acaba se configurando com uma violência estrutural, levando a expropriação da terra, a exploração de mão de obra do campo, os desmatamentos dos recursos ambientais, ou seja, negando o direito de existir dos sujeitos do campo em seus próprios territórios (Tardin, 2012). Assim, podemos definir que a TO Social realizará suas ações levando em conta dois processos:

- Processos macrossociais: como as condições territoriais, que no campo se constituem em conflitos com grandes latifundiários, e a resistência dos movimentos sociais; as características específicas das comunidades (sejam elas ribeirinhas, tradicionais, assentados, atingidos por barragem, quilombolas, pescadores, entre outros), tendo em vista que cada um possui suas particularidades culturais e históricas; mapeamento das redes de suporte, tendo em vista que a atuação sobre essas questões precisam se constituir de forma intersetorial, com os diversos núcleos de saberes (política, administrativa, assistencial social, saúde, educação, cultura, justiça) (Malfitano, 2005);

Processos microssociais: relacionados às histórias de vida; modos de viver, trabalhar, se expressar, falar, se 
vestir, todos os aspectos culturais, agindo assim sobre os modos de vida dos sujeitos, os valorizando culturalmente, não esquecendo que a constituição desses sujeitos perpassa por histórias de luta, resistência e resiliência; suas subjetividades e processos de singularidades, maneiras de se relacionar com o mundo, modos de subjetivação e configurações da subjetividade, singularização dos processos individuais e coletivos dentro das conjunturas atuais e os aspectos históricos, valorizando suas identidades (Lopes \& Silva, 2007).

A TO Social vai agir nas Escolas do Campo dando conta dessas questões e legitimando os movimentos sociais dos trabalhadores do campo, contribuindo para a superação dessas problemáticas do campo.

As ações efetivas da TO Social nos ambientes Escolares do Campo podem ocorrer com intervenções de produção individual e coletiva, utilizando as atividades, tendo em vista que esse é o recurso terapêutico historicamente utilizado pela profissão (Barros, Lopes \& Galheigo, 2007a). Assim, “a Terapia Ocupacional Social utiliza as atividades como um recurso mediador do trabalho de aproximação, acompanhamento, apreensão das demandas e fortalecimento dos sujeitos individuais e coletivos, para os quais direciona sua ação". (Lopes et al., 2014, p. 594-595).

E nesse contexto a atividade tomará um caráter emancipatório, tendo como parâmetro as questões históricas e culturais dos sujeitos que irão vivenciar esse processo de intervenção, sendo fundamental que essas possuam significado para os sujeitos (Barros, Lopes \& Galheigo, 2007b). Além disso, deve-se levar em conta que a escola é um local de encontro que produz significados e interfere de maneira direta na existência desses sujeitos do campo.

As ações práticas da TO Social podem se dar de diversas formas, com base nas tecnologias sociais inovadoras, a fim de produzir ações que articulem e agreguem dimensões micro e macrossociais. Algumas ações da profissão nas escolas do campo podem se dar das seguintes maneiras:

- Construção de Atividades, Dinâmicas e Projetos, constituindo espaços coletivos ou grupais: utilizar atividades grupais ou coletivas, com intuito de conhecer os universos desses sujeitos que constituem o ambiente escolar do campo (alunos, profissionais da educação e comunidade), buscando ampliar os vínculos com as atividades significativas, de cunho cultural, que caracterizam o viver no campo. As atividades grupais se 
constituem como espaços de produção de conhecimento, troca de experiência, que desenvolve papel fundamental na constituição subjetiva dos sujeitos envolvidos. Além disso, as atividades grupais são um instrumento com vastas finalidades, podendo ser uma estratégia para atuar das seguintes maneiras: utilizando técnicas intrínsecas de atividades (culinária, manejo com a terra); realizar atividades utilizando e construindo diversos materiais (artesanais, fotografia, origami); uso de atividades esportivas, de expressão corporal, dança e lazer; fazer grupos de diálogos sobre questões que envolvem histórias de vidas e projetos de vida; trabalhar fatos relacionados com o cotidiano (estudar, alimentar-se, brincar, namorar, jogar, brincar) de viver no campo, suas necessidade e experiências; discutir questões do cotidiano escolar do campo, seus conflitos, suas importâncias, estratégias de enfrentamento coletivo sobre questões problemas; construção de espaços coletivos no ambiente escolar (hortas, grupos de leitura); parcerias com professores de diversas disciplinas, potencializando os temas das salas de aula nas atividades grupais; entre outra coisas (Lopes, et al., 2014, p. 597).

Esse espaço se configura como lugar de sociabilidade, aprendizagem e experimentação, objetivando contribuir para que os sujeitos que participarem dela adquiram novas leituras sobre o mundo do campo, sobre suas próprias identidades, sempre as desenvolvendo com o objetivo de trazer a cultura camponesa, pautada na Agricultura Camponesa, seus modos de vida, suas histórias de luta e resistência, os valorizando e ressignificando. Objetivando desmitificar os pensamentos hegemônicos que os coloca como "lugar de atraso" e que marginaliza seus modos de vida. Desencadeando processos de subjetivação que empoderem esses sujeitos sobre suas existências. Busca-se contribuir também para que os profissionais da educação das escolas do campo possam superar olhares reducionistas sobre o campo e seus sujeitos (Silva, 2011). Além disso, essas ações podem contribuir para "a discussão acerca da construção de propostas educativas no interior da escola pública, fundadas em bases democráticas, que se aproximem mais das necessidades e realidade dos alunos" (Lopes, et al., 2014, p. 597) do campo.

- Acompanhamentos singulares e territoriais: estratégias de intervenção com o objetivo de compreender o território do camponês, de maneira mais intensa, o que possibilidade realizar uma leitura da realidade concreta, circulando sobre as redes de relações que estão em volta das Escolas do Campo, compreende aquele 
território como espaço vivo. Fortalecendo a ponte entre comunidade e cotidiano escolar. Essas necessidades se dão pelas demandas singulares ou coletivas, também podendo ser acionada para buscar a realidade específica de um indivíduo, que por algum problema familiar, causado pelas desigualdades sociais exige um acompanhamento mais próximo sobre suas vivências, entendendo que a vida escolar dos sujeitos é dependente das vidas familiares, comunitárias e de trabalho (Lopes, et al., 2014).

\section{- Articulação de Recursos no Campo}

Social: essas articulações se constroem a partir de diversas articulações individuais, coletivas, institucionais e políticas, com a finalidade de lançar mão de estratégias para gerenciar práticas nos distintos níveis de atenção social, com o intuito de alcançar os "objetivos comuns e utilizar os recursos possíveis, compreendidos como dispositivos financeiros, materiais, relacionais, afetivos, sejam eles micro ou macrossociais, para compor as intervenções” (Lopes, et al., 2014, p. 598). Assim, estratégias de intervenção articuladas, negociando os recursos disponíveis para subsidiar uma educação de qualidade nas escolas do campo. Fortalecendo as ações políticas públicas para os alunos inseridos nas escolas do campo, bem como para os professores e familiares.

\section{- Dinamização da Rede de Serviços:} essa ação realizada pela TO Social objetiva mapear, organizar e materializar todos os programas, projetos e movimentos que são voltados para a comunidade do campo "com o intuito de fomentar a interação e a integração entre eles, articulando os diferentes setores e níveis de intervenção, facilitando a efetividade e o direcionamento das estratégias". (Lopes, et al., 2014, p. 598). Assim, com a articulação de diversas ações se torna possível à realização da construção da uma rede social resolutiva para os sujeitos do campo, pautadas na intersetoralidade e interdisciplinaridade, e que tenha a Educação do Campo como um movimento fundamental para a sustentação dessa rede. Além disso, o intuito também é fortalecer essas redes para os profissionais da educação, para esses se apropriarem dos projetos que são realizados, se correponsabilizando sobre essas ações, para que assim tenham respostas para as demandas e necessidades sociais dos sujeitos do campo.

\section{Considerações finais}

A TO Social vai atuar fortalecendo os processos da Educação do Campo, 
assegurando o acesso da população do campo aos seus direitos sociais, em especial educacionais, articulando ações terapêuticas ocupacionais para ajudar a promover nos ambientes escolares do campo uma escola que esteja estreitamente fixada nas necessidades sociais dos camponeses, que não reproduza qualquer tipo de opressão institucional. Intermediando através de atividades relações que superem a concepção de campo como lugar marginalizado e atrasado, exaltando seus valores culturais, sociais e as existências dos diversos sujeitos que o torna um território heterogêneo. Lutando por uma escola pública, sendo esse fator fundamental para uma escola igualitária e democrática no nosso país.

Essas reflexões buscaram direcionar os papéis possíveis da TO no campo, sendo então de fundamental importância a inserção desses profissionais nas escolas do campo, compreendendo que os processos de construção para uma realidade do campo mais justa e emancipatória depende da atuação interdisciplinar, fortalecendo os movimentos. Assim, esse estudo buscou abrir as porteiras para novas reflexões, e para apontar que esse é um campo possível que deve ser explorado pela TO Social.

\section{Referências}

Althusser, L. (1970). Ideologia $e$ Aparelhos ideológicos de estado. Lisboa: Presença.

Barros, D. D., Lopes, R. E., \& Galheigo, S. M.(2007a). Terapia Ocupacional Social: Concepções e Perspectivas. In Cavalcanti, A., \& Galvão, C. (Org.). Terapia Ocupacional: fundamentação e prática (pp.347-353). Rio de Janeiro: Guanabara Koogan.

Barros, D. D., Lopes, R. E., \& Galheigo, S. M. (2007b). Novos espaços, novos sujeitos: a terapia ocupacional no trabalho territorial e comunitário. In Cavalcanti, A., \& Galvão, C. (Org.), Terapia Ocupacional: fundamentação e prática (pp. 354-363). Rio de Janeiro: Guanabara Koogan.

Bartalotti, C. (2007). Deficiência mental. In Cavalcanti, A., \& Galvão, C. (Org.). Terapia Ocupacional: fundamentação $e$ prática (pp. 295-298). Rio de Janeiro: Guanabara Koogan.

Bezerra, W. C. (2011). O Estado Brasileiro e o Ataque Neoliberal: Algumas reflexões para a Terapia Ocupacional. Cadernos de Terapia Ocupacional da UFSCar, 19(2), 239-248.

Caldart, R. S. (2008). Sobre educação do campo. In: Santos, C. A. (Org.), Educação do campo: campo - políticas públicas educação (pp. 67-97). Brasília: INCRA; MDA.

Caldart, R. S. (2012). Educação do Campo. In: Caldart, R. S. et al. (Org.). Dicionário da Educação do Campo (pp. 257-264). Rio de Janeiro: Escola Politécnica de Saúde Joaquim Venâncio, Expressão Popular. 
Cardoso, P. T., \& Matsukura, T. S. (2012). Práticas e perspectivas da terapia ocupacional na inclusão escolar. Rev. Ter. Ocup. Univ. São Paulo, 23(1), 7-15.

Carvalho, R. A. (2011). A construção da identidade e da cultura dos povos do campo, entre o preconceito e a resistência: o papel da educação. (Tese de Doutorado). Universidade Metodista de Piracicaba, São Paulo.

Costas Jr., W. R. (2010). Política Educacional no contexto do Neoliberalismo. Revista da Faculdade de Educação, 13(8), 31-49.

Cruz A. B., Araújo L. A., \& Costa T. M. M. (2015). Cultura Rural: Resistências e Modificações Observadas no Campo a partir da Inserção da Tecnologia. In Anais do $2^{\circ}$ Workshop de Geografia Cultural: da Cultura Material ao Simbolismo Cultural (pp.99-109). Alfenas - MG.

Freire, P. (1967). Educação como prática da liberdade. Rio de Janeiro, Paz e Terra.

Gentili, P. (Org.). (1995). Pedagogia da exclusão: crítica ao neoliberalismo em educação. Petrópolis: Vozes.

Guhur, D. M. P., \& Silva, I. M. S. (2009). As Políticas Sociais Neoliberais no Quadro da Mundialização do Capital: Um "Movimento Em Busca Dos Anéis Sacrificados No Passado Para Salvar Os Dedos". Revista HISTEDBR On Line, 35, 76-95.

Lopes, R. E., \& Silva, C. R. (2007). O campo da educação e demandas para a terapia ocupacional no Brasil. Rev. Ter. Ocup. Univ. São Paulo, 18(3), 158-164.

Lopes, R. E., Borba, P. L. O., \& Cappellaro, M. (2011). Acompanhamento individual e articulação de recursos em Terapia Ocupacional Social: compartilhando uma experiência. $O$ Mundo da Saúde, 35(2), 233-238.

Lopes, R. E. et al. (2010). Educação profissional, pesquisa e aprendizagem no território: notas sobre a experiência de formação de terapeutas ocupacionais. $O$ Mundo da Saúde, 34(2), 140-147.

Lopes, R. E. et al. (2014). Recursos e tecnologias em Terapia Ocupacional Social: ações com jovens pobres na cidade. Cad. Ter. Ocup, 22(3), 591-602.

Leher, R., \& Motta, V.C. (2012). Políticas Educacionais Neoliberais e Educação do Campo. In: Caldart, Roseli et al. (Org.). Dicionário da Educação do Campo (pp. 576-585). Rio de Janeiro: Escola Politécnica de Saúde Joaquim Venâncio, Expressão Popular.

Malfitano, A. P. S. (2005). Campos e núcleos de intervenção na terapia ocupacional social. Rev. Ter. Ocup. Univ. São Paulo, 16(1), 1-8.

Martins, F. J. (2009). Educação do Campo: processo de ocupação social e escolar. In Anais do Congr. Intern. Pedagogia Social (pp. 204-220) São Paulo - SP.

Molina, C. M. (2006). Prefácio. In Caldart, R. S., Paludo, C., \& Doll, J. (Org.). Como se formam os sujeitos do campo? Idosos, adultos, jovens, crianças e educadores (pp.07-10). Brasília: PRONERA: NEAD.

Molina, C. M. (2009). Possibilidades e Limites de Transformações das escolas do campo: reflexões suscitadas pela Licenciatura em Educação do Campo UFMG. In Antunes-Rocha, M. I., \& Martins, A. A. (Org.). Educação do Campo: desafios para a formação de professores (pp.185-198). Belo Horizonte: Autêntica Editora, Coleção Caminhos da Educação do Campo 1. 
Molina, M. C. (2010). Reflexões sobre o significado do protagonismo dos Movimentos Sociais na construção de Políticas Públicas de Educação do Campo. In Molina, M. C. (Org.). Educação do Campo e Pesquisa: questões para reflexão II. Brasília: MDA/MEC.

Molina, C. M. (2015). Expansão das licenciaturas em Educação do Campo: desafios e potencialidades. Educar em Revista, 55, 145-166.

Molina, C. M., \& Sá, L. M. (2012). Escola do Campo. In Caldart, R. et al. (Org.). Dicionário da Educação do Campo (pp. 324-331). Rio de Janeiro: Escola Politécnica de Saúde Joaquim Venâncio, Expressão Popular.

Montaño, C. (2007). Terceiro setor $e$ questão social: crítica ao padrão emergente de intervenção social. São Paulo: Cortez.

Munguba, M. C. S. (2008). Terapia Ocupacional em ação interdisciplinar: jogos educativos-nutricionais na prevenção da obesidade infantil. (Tese de Doutorado), Universidade Federal do Rio Grande do Sul, Rio Grande do Sul.

Oliveira, L. M. T., \& Campos, M. (2012). Educação básica do campo. In Caldart, R. et al. (Org.). Dicionário da Educação do Campo (pp. 237-250). Rio de Janeiro: Escola Politécnica de Saúde Joaquim Venâncio, Expressão Popular.

Rocha, E. F. (2007). A Terapia Ocupacional e as ações na educação: aprofundando interfaces. Rev. Ter. Ocup. Univ. São Paulo, 18(3), 122-127.

Saviani, D. (2008). Escola e Democracia. Edição Comemorativa. Campinas: Autores Associados.
Silva, C. R. (2011). Percursos juvenis e trajetórias escolares: vidas que se tecem nas periferias das cidades. (Tese de Doutorado). Universidade Federal de São Carlos, São Paulo.

Silva, C. R. (2016). Juventude e educação: a trajetória constituída pelo não lugar. In Lopes, R. E., \& Malfitano, A. P. S. (Orgs.). Terapia Ocupacional Social: desenhos teóricos e contornos práticos. São Carlos: EdUFSCar.

Silveira, D. T., \& Córdova, F. P. (2009). Unidade 2 - A Pesquisa Científica. In Gerhardt, T. E., \& Silveira, D. T. Métodos de pesquisa (pp.31-42). Porto Alegre: Editora da UFRGS.

Tardin, J. M. (2012). Cultura Camponesa. In Caldart, R. et al. (Org.). Dicionário da Educação do Campo (pp. 178-186). Rio de Janeiro: Escola Politécnica de Saúde Joaquim Venâncio, Expressão Popular.

\footnotetext{
i Compreende-se interdisciplinaridade como "a comunicação e o trabalho conjunto entre os diferentes atores para composição de uma rede de intervenção" (Malfitano, 2005, p. 04). Desta forma, quando refere-se a interdisciplinaridade nas escolas do campo, pontua-se a necessidade de outros atores, como o TO Social, para contribuir com o trabalho dos educadores, dos diretores e demais profissionais de educação, buscando consolidar o modelo de escola do campo veiculado pelo movimento de Educação do Campo.
}

Recebido em: 18/02/2017 Aprovado em: 30/03/2017 Publicado em: 31/07/ 2017 
Como citar este artigo / How to cite this article / Como citar este artículo:

APA:

Farias, M. N., \& Faleiro, W. (2017). Contribuições da Terapia Ocupacional Social nas escolas do campo. Rev. Bras. Educ. Camp., 2(2), 542-562. DOI: http://dx.doi.org/10.20873/uft.2525-

$\underline{4863.2017 \mathrm{v} 2 \mathrm{n} 2 \mathrm{p} 542}$

ABNT:

FARIAS, M. N.; FALEIRO, W. Contribuições da Terapia Ocupacional Social nas escolas do campo. Rev. Bras. Educ. Camp., Tocantinópolis, v. 2, n. 2, p. 542-562, $2017 . \quad$ DOI: http://dx.doi.org/10.20873/uft.25254863.2017v2n2p542

\section{ORCID}

\section{Magno Nunes Farias}

iD http://orcid.org/0000-0002-9249-1497

Wender Faleiro

(iD) http://orcid.org/0000-0001-6419-296X 